\title{
Variação de umidade absoluta e temperatura do ar intraurbano nos arredores de um corpo d'água
}

\author{
Variation of absolute humidity and air temperature in the \\ urban canopy layer in the surroundings of a water body
}

\section{Erico Masiero \\ Léa Cristina Lucas de Souza}

\section{Resumo \\ $\mathbf{E}$}

ste estudo tem por objetivo verificar a distribuição de umidade absoluta e da temperatura do ar intraurbano, associando-as à presença de um corpo d'água na área urbana de São José do Rio Preto, SP. A combinação do conteúdo de água no ar fornecido por corpos d'água com o potencial eólico pode favorecer significativamente as condições microclimáticas de uma área urbana, levando a um ambiente térmico mais ameno. Nove pontos de coleta de dados foram selecionados na malha urbana para detectar diferenças de temperatura e umidade absoluta do ar. Quatro pontos detalham os fenômenos físicos associados às trocas de calor intraurbanas sob a influência da distribuição da umidade absoluta. Foi detectado que o ponto de coleta à margem da represa municipal permaneceu aproximadamente $2^{\circ} \mathrm{C}$ abaixo do ponto situado na zona residencial mais impermeabilizada e $7 \mathrm{~g} / \mathrm{m}^{3}$ mais úmido. A alta variação dos valores de umidade absoluta detectada neste estudo corrobora a necessidade de criação de estratégias para a redução da evaporação e melhoria da distribuição da quantidade de água no ar pelos espaços intraurbanos em épocas quentes e secas em cidades situadas em áreas continentais.

Palavras-chave: Corpos d'água. Umidade. Ventilação urbana. Ambiente térmico urbano.

\begin{abstract}
This study aims to verify the distribution of absolute humidity and variation of air temperature in the urban canopy layer, linking them to the presence of a water body in the town of São José do Rio Preto, SP. The combination of the moisture content in the air provided by a water body and the blowing potential of the wind may strongly affect the microclimate conditions of an urban area, leading to a milder thermal environment. Nine data collection points were distributed throughout the urban fabric in order to detect differences in air temperature and absolute air humidity. Four of them were chosen to detail the physical

phenomenon associated to the heat exchange in the urban canopy layer according to the absolute humidity distribution. The point located close to the banks of the reservoir maintained an average temperature $2^{\circ} \mathrm{C}$ lower than the point located on a paved area, and its was $7 \mathrm{~g} / \mathrm{m}^{3}$ more humid. The high rates of variation of absolute humidity detected in this study justify the need to create strategies to reduce evaporation and to improve absolute humidity distribution throughout the urban canopy layer in dry and warm periods in urban areas situated on continental regions.
\end{abstract}

Erico Masiero Universidade Federal de São Carlos São Carlos - SP - Brasil

Léa Cristina Lucas de Souza Universidade Federal de São Carlos São Carlos - SP - Brasil

Recebido em 11/04/13 Aceito em 08/07/13
Keywords: Water bodies. Absolute humidity. Urban ventilation. Urban thermal environment.

MASIERO, E.; SOUZA, L. C. L. de. Variação de umidade absoluta e temperatura do ar intraurbano nos arredores de um 25 corpo d'água. Ambiente Construído, Porto Alegre, v. 13, n. 4, p. 25-39, jul./set. 2013.

ISSN 1678-8621 Associação Nacional de Tecnologia do Ambiente Construído. 


\section{Introdução}

A diversidade de padrões de ocupação urbana propostos pelas administrações públicas municipais brasileiras raramente considera no planejamento urbano os fatores climáticos e os princípios físicos associados às trocas de calor, de tal forma que os benefícios da permeabilidade ao vento e da distribuição da umidade do ar não são explorados. Assim, em uma mesma cidade são formados ambientes que podem privilegiar a qualidade térmica de determinadas áreas em detrimento de outras, de acordo com os padrões construtivos adotados.

Algumas dessas diferenças da qualidade térmica são exemplificadas por Yuan et al. (2011) e Chen e $\mathrm{Ng}$ (2011), ao analisarem como as modificações na geometria urbana em Hong Kong afetam as condições de conforto dos habitantes. No entanto, aqueles mesmos autores, com o auxílio de mapas climáticos, demonstram que é possível propor aos planejadores recomendações de como ocupar o território e aproveitar ao máximo os recursos naturais, para a obtenção de um ambiente urbano menos agressivo ao ser humano.

Alterações climáticas locais nos diversos espaços urbanos estão relacionadas às transformações de energia, influenciadas pela morfologia do sítio, pelas propriedades térmicas dos materiais das superfícies construídas e pela produção antropogênica de calor (ASSIS, 2006). Em geral, o ambiente urbano apresenta valores mais elevados de temperaturas e de umidade que o ambiente rural. Kuttler et al. (2007), analisando as diferenças de umidade entre ambiente rural e urbano na cidade de Krefeld, na Alemanha, indicam que o ambiente urbano é em geral mais úmido que o ambiente rural, porque a área urbana apresenta menos superfícies de evaporação que a área rural. A baixa densidade construída na cidade, a grande quantidade e distribuição de espaços verdes e a ausência de áreas industriais possibilitam efeitos climáticos mais estáveis e amenos, quando comparados a cidades com superfícies altamente impermeabilizadas.

Aspectos da influência do desenho urbano no ambiente térmico são estudados por Mitchell et al. (2007), em Melbourne, na Austrália, que procuram demonstrar o impacto da variação do ciclo hidrológico nas estratégias de armazenamento, para uso da água na irrigação e para evaporação. A pesquisa confirma o potencial de controle passivo do microclima urbano pelo desenho das áreas suburbanas, maximizando a evapotranspiração com a presença de espaços verdes e de tetos vegetados das construções. Aquele estudo sugere que os investimentos na manutenção e na irrigação de áreas verdes na periferia podem retornar em benefícios tanto na eficiência energética nos edifícios dos centros urbanos como na manutenção da qualidade do ar.

Grimmond e Oke (1999) estimaram que as perdas de água por evapotranspiração giram entre $40 \%$ e $80 \%$ nos balanços anuais de verão para cidades da América do Norte. No entanto, a estimativa completa dos volumes de circulação de água em áreas urbanas, tanto de origem natural quanto antropogênica, é, segundo Arnfield (2003), uma questão que ainda requer aprofundamento. As intervenções físicas no meio podem alterar o regime natural da evapotranspiração de determinada região, por isso é importante elucidar a interação das superfícies d'água disponíveis com a camada intraurbana e a influência da transmissão do calor e do vapor d'água através do movimento horizontal das massas de ar. $\mathrm{O}$ aproveitamento do potencial eólico de determinado local, combinado com a umidade fornecida por corpos d'água ou pela vegetação, pode favorecer às condições microclimáticas de uma cidade e torná-las mais agradáveis, conforme as condições de tempo apresentadas.

Nas áreas urbanas pode ainda ocorrer redução das taxas de resfriamento evaporativo e convectivo, consequência da cobertura sistemática do solo, da redução de áreas de vegetação, de infiltração e dos corpos d'água superficiais, bem como a redução da velocidade dos ventos, causada pelo aumento da rugosidade superficial (ASSIS, 2006). Emmanuel e Johansson (2006), examinando a influência da brisa marítima e da morfologia urbana no microclima de Colombo, Sri Lanka, verificaram que há pouca ventilação nos cânions urbanos devido aos ventos moderados e ao posicionamento das massas construídas. Por isso, aqueles autores sugeriram um rearranjo do desenho da cidade, de forma a permitir a permeabilidade ao vento e a distribuição mais homogênea dos ventos marítimos pela malha urbana.

A distribuição da ventilação natural dos espaços urbanos ocorre pelos cânions urbanos e através dos fundos de vales dos rios, onde os lagos podem ser formados. O amplo espaço aberto que os corpos d'água ocupam, juntamente com a vegetação ciliar, contribui para a amenização significativa do calor, para a melhoria da qualidade do ar e para a distribuição dos fluxos de vento para os centros urbanos.

De uma forma geral, os corpos d'água promovem o resfriamento evaporativo. O princípio básico do resfriamento evaporativo adiabático consiste na 
evaporação das gotículas de um corpo d'água em ambiente urbano, mediante seu contato com o ar em movimento. A energia necessária para que o processo de evaporação ocorra é fornecida pelo ar, que cede calor sensível às gotículas de água, as quais passam do estado líquido para o gasoso.

Um corpo d'água urbano pode criar zonas de ventilação mais favoráveis à dispersão dos poluentes da atmosfera. Por ocupar grandes áreas abertas, situar-se nas cotas inferiores e possuir poucos obstáculos e pouca rugosidade nas superfícies, esta região contribui para aumentar a pressão atmosférica local e renovar mais frequentemente $\mathrm{o}$ ar urbano. Dessa maneira, o aumento das taxas de umidade provocado pela evaporação da água e a consequente redução da temperatura do ar podem reduzir as amplitudes térmicas urbanas.

A compreensão dos fenômenos microclimáticos provenientes da evaporação dos corpos d'água e a distribuição da umidade são de fundamental importância para subsidiar a implantação de intervenções espaciais como represamento de córregos e estabelecimento de parâmetros de ocupação urbana. Diretrizes de planejamento urbano apresentadas por Monteiro e Mendonça (2011) para Londrina, no Paraná, destacaram que o represamento de partes de alguns cursos hídricos para a formação de lagos e espaços verdes pode contribuir com a umidificação atmosférica e amenizar os efeitos da continentalidade climática regional.

Buscando compreender como as estratégias de umidificação do ar podem atuar em uma cidade, este artigo tem como objetivo verificar a distribuição de umidade absoluta e temperatura do ar intraurbano, associando-as à presença de um corpo d'água na área urbana de São José do Rio Preto, SP.

\section{Método}

Os procedimentos metodológicos deste estudo são baseados em seis etapas:
(a) caracterização física da área de estudo;
(b) seleção de pontos e disposição de sensores para coleta de dados;

(c) monitoramento, coleta e analogia entre dados observados e dados meteorológicos;

(d) determinação de janela de tempo para análise dos dados;

(e) modelagem de dados e localização de informações através de mapeamento; e

(f) análise gráfica e qualitativa da distribuição da temperatura e da umidade absoluta.

A Figura 1 apresenta um fluxograma resumido desses procedimentos.

\section{Caracterização geral da área de estudo}

São José do Rio Preto está localizada a noroeste do Estado de São Paulo, nas coordenadas 20 49' 11" de latitude sul e $49^{\circ} 22^{\prime} 46^{\prime \prime}$ de longitude oeste. A área urbana corresponde a $117,43 \mathrm{~km}^{2}$ e é cortada por um rio de pequeno porte, o Rio Preto, que junto com o córrego dos Macacos formam uma represa municipal na área sul da cidade. A cidade está localizada em altitudes próximas aos $500 \mathrm{~m}$ em relação ao nível do mar, e os biomas são caracterizados pela presença marcante de Cerrados e resquícios de Mata Atlântica, segundo o IBGE (2013).

\section{Figura 1 - Fluxograma dos procedimentos metodológicos}

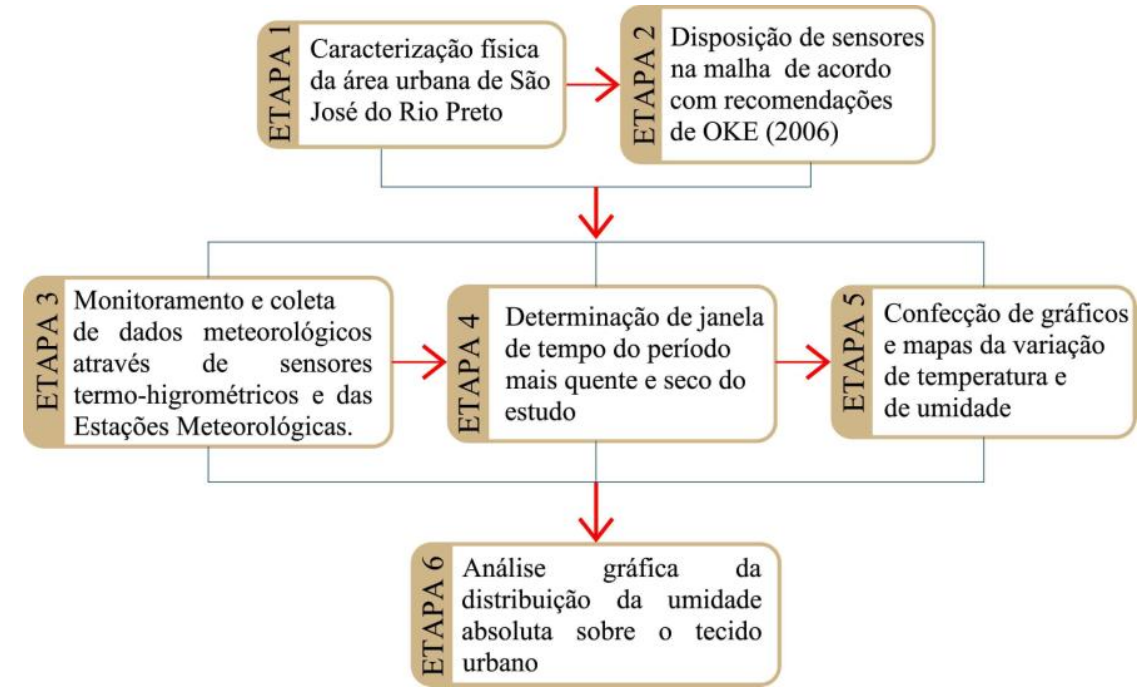


O sítio sobre o qual se implantou a cidade de São José do Rio Preto é caracterizado por um relevo pouco ondulado, com espigões amplos e de modesta altitude. As rodovias Transbrasiliana BR153, na direção NE-SW, e a Washington Luiz SP310, na direção E-W, influenciaram o direcionamento do crescimento da cidade. A maior concentração populacional da cidade de São José do Rio Preto está contida a noroeste do entroncamento das duas principais rodovias, atualmente com 420 mil habitantes aproximadamente (PREFEITURA..., 2013b).

A área de espelho d'água da represa municipal chega a aproximadamente $9 \mathrm{~km}^{2}$ e, após o tratamento, é responsável pelo abastecimento de $30 \%$ a $40 \%$ da água potável do município (Figuras 2 e 3$)$.

A zona norte da cidade caracteriza-se pelos baixos índices de áreas verdes, ocupação predominantemente residencial unifamiliar de baixa renda, em elevadas cotas topográficas, o que a coloca entre as mais áridas da cidade. O estudo de Rocha, Souza e Castilho (2011) evidencia outras características do local

A atuação da dinâmica climática da região é abordada neste estudo como uma variável que influencia o comportamento higrotérmico do ambiente construído, tendo em vista os efeitos do resfriamento proporcionado pela represa municipal, que possam adequar o ambiente construído às necessidades do conforto humano. Nimer (1979) relata que fatores de ordem estática e natureza dinâmica definem os processos climatológicos da Região Sudeste, onde está situada São José do Rio Preto, e recebe influências das perturbações climáticas típicas dessa região. Segundo o mesmo autor, a Região Sudeste está localizada sob a trajetória preferida das frentes polares, e frequentemente o sistema de circulação do anticiclone polar das altas latitudes e o sistema de circulação dos anticiclones do Atlântico Sul das baixas latitudes se combinam em equilíbrio dinâmico, fato que caracteriza a diversificação do clima da região.

De acordo com Monteiro (1973), o território paulista é vulnerável à ação das principais correntes da circulação atmosférica da América do Sul. As massas, Tropical Atlântica e Continental, Polar Atlântica e Equatorial Continental, juntamente com os fatores geográficos de posicionamento e relevo contribuem para definir as características de climas tropicais, alternadamente secos e úmidos.

Figura 2 - Vista panorâmica da represa municipal e área central de São José do Rio Preto

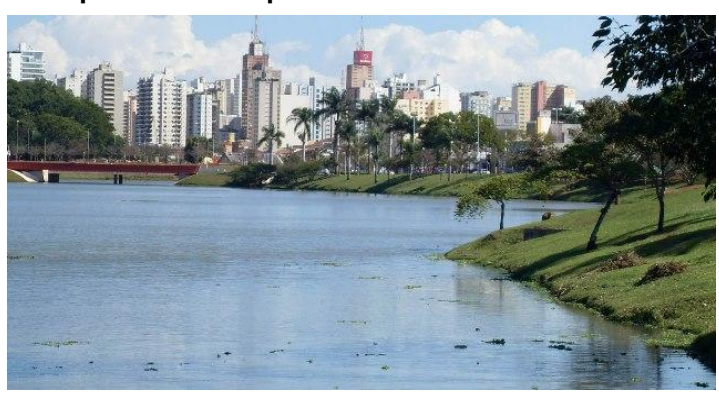

Fonte: foto do autor (2009).

Figura 3 - Vista aérea da represa municipal e área central de São José do Rio Preto

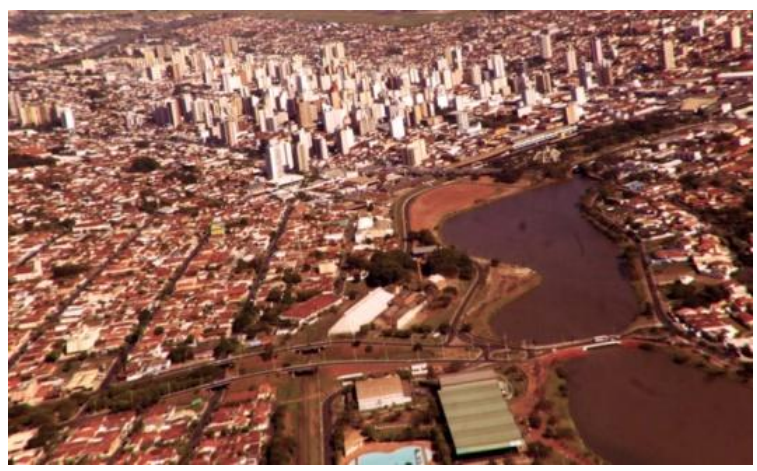

Foto: foto do autor (2011) 


\section{Seleção de pontos e disposição de sensores para coleta de dados}

Oke (2006) sugere uma classificação em Zonas Climáticas Urbanas (Urban Climate Zones - UCZ) para descrever áreas representativas a serem estudadas. Essa classificação permite identificar o potencial de cada área em alterar o clima local e caracterizar a transição entre as diferentes áreas. As escalas são conferidas pelas dimensões das características morfológicas que compõem a paisagem urbana, assim é necessário descrever as propriedades das áreas urbanas que podem afetar a atmosfera em relação à estrutura, à cobertura das superfícies, ao tecido e ao metabolismo urbano. Segundo Mills et al. (2010), o acesso e o entendimento dos dados relativos à infraestrutura dos espaços construídos e dos dados macro, meso e microclimáticos oferecem informações e estabelecem uma compreensão mais ampla da dinâmica urbana, inclusive sob os aspectos econômicos sociais e demográficos. Dessa forma, a vulnerabilidade climática e os possíveis efeitos maléficos da apropriação do espaço urbano podem ser considerados em projetos de intervenção.

Nove pontos de monitoramento foram selecionados de acordo com as recomendações feitas por Oke (2006), os quais foram utilizados para a confecção de um mapa de variação de temperatura e outro de distribuição de umidade absoluta. Desses, quatro pontos que apresentaram as variações de dados mais evidentes foram detalhados graficamente (Figuras 4 e 5).

O ponto 1 localiza-se em uma área rural no extremo sul de São José do Rio Preto, com atividades predominantemente baseadas na agricultura familiar e em imóveis rurais de veraneio. Os dados foram coletados pela Estação Meteorológica do Centro Integrado de Informações Agrometeorológicas (CENTRO..., 2013c), do Instituto Agronômico de Campinas (IAC), que está situada nas proximidades dos pontos de interesse. O padrão da altura da medição da estação do IAC é de aproximadamente $2 \mathrm{~m}$ acima da superfície (ROCHA; SOUZA; CASTILHO, 2011). O sensor de temperatura e umidade utilizado é um HMP45, da Campbell, cuja faixa de medição de temperatura vai de $-39,2$ ${ }^{\circ} \mathrm{C}$ a $60^{\circ} \mathrm{C}$, com precisão de $\pm 0,5^{\circ} \mathrm{C}$.

$\mathrm{O}$ ponto 2 localiza-se na margem sul da represa municipal e, apesar de estar localizado próximo ao centro urbano, possui baixa densidade construída. Dessa forma, o sensor está sujeito à direta influência da umidade disponibilizada pelo lago e exposto à ação do vento. $\mathrm{O}$ ponto 2 foi posicionado no fundo do vale do Rio Preto, o qual apresenta as mais baixas cotas topográficas entre todas as áreas de estudo.

O ponto 3 foi estabelecido na Estação Meteorológica da Companhia de Tecnologia de Saneamento Ambiental (COMPANHIA..., 2013), a qual está localizada na área periférica da cidade, em um bairro predominantemente residencial da zona norte da cidade, a $5 \mathrm{~km}$ a noroeste da represa municipal. É uma estação de monitoramento automático que disponibiliza dados relativos à qualidade do ar urbano, dos parâmetros meteorológicos e de níveis de poluentes presentes no ar. Nela, o equipamento utilizado é um termohigrômetro, instalado a uma altura de $2 \mathrm{~m}$ em relação ao solo. A faixa de trabalho para temperatura do ar está entre $-30{ }^{\circ} \mathrm{C}$ e $70{ }^{\circ} \mathrm{C}$, com precisão de medida de $\pm 0,1^{\circ} \mathrm{C}$ (COMPANHIA..., 2013).

O ponto 4 também está situado na zona norte da cidade, a $6,5 \mathrm{~km}$ a noroeste da represa municipal. Essa área caracteriza-se por uma ocupação de residências térreas unifamiliares, com taxa de ocupação de aproximadamente $60 \%$, baixo índice de áreas verdes e solo altamente impermeabilizado. Esse ponto, assim como o ponto 3 , está localizado na área mais elevada da cidade (Figuras 4, 5 e 6).

\section{Monitoramento, coleta e analogia entre dados coletados e dados meteorológicos}

Os dados de temperatura e umidade intraurbanos nos pontos 2 e 4 foram coletados com os sensores HOBO Pro V2 U23-001, dispostos dentro de protetores ventilados de PVC, em locais sujeitos à radiação solar direta, na face sul de postes frontais internos aos lotes urbanos, a $3 \mathrm{~m}$ de altura em relação ao solo urbano, conforme recomendações e especificações do fabricante (Figuras 7 e 8). Para a coleta desses dados foram realizados registros horários durante 15 dias no período de 1/10/2012 a $16 / 10 / 2012$. Após a coleta foi verificada a janela de tempo que melhor representasse o período mais seco, conforme descrito no item específico. 
Figura 4 - Localização dos nove pontos de monitoramento e coleta de dados

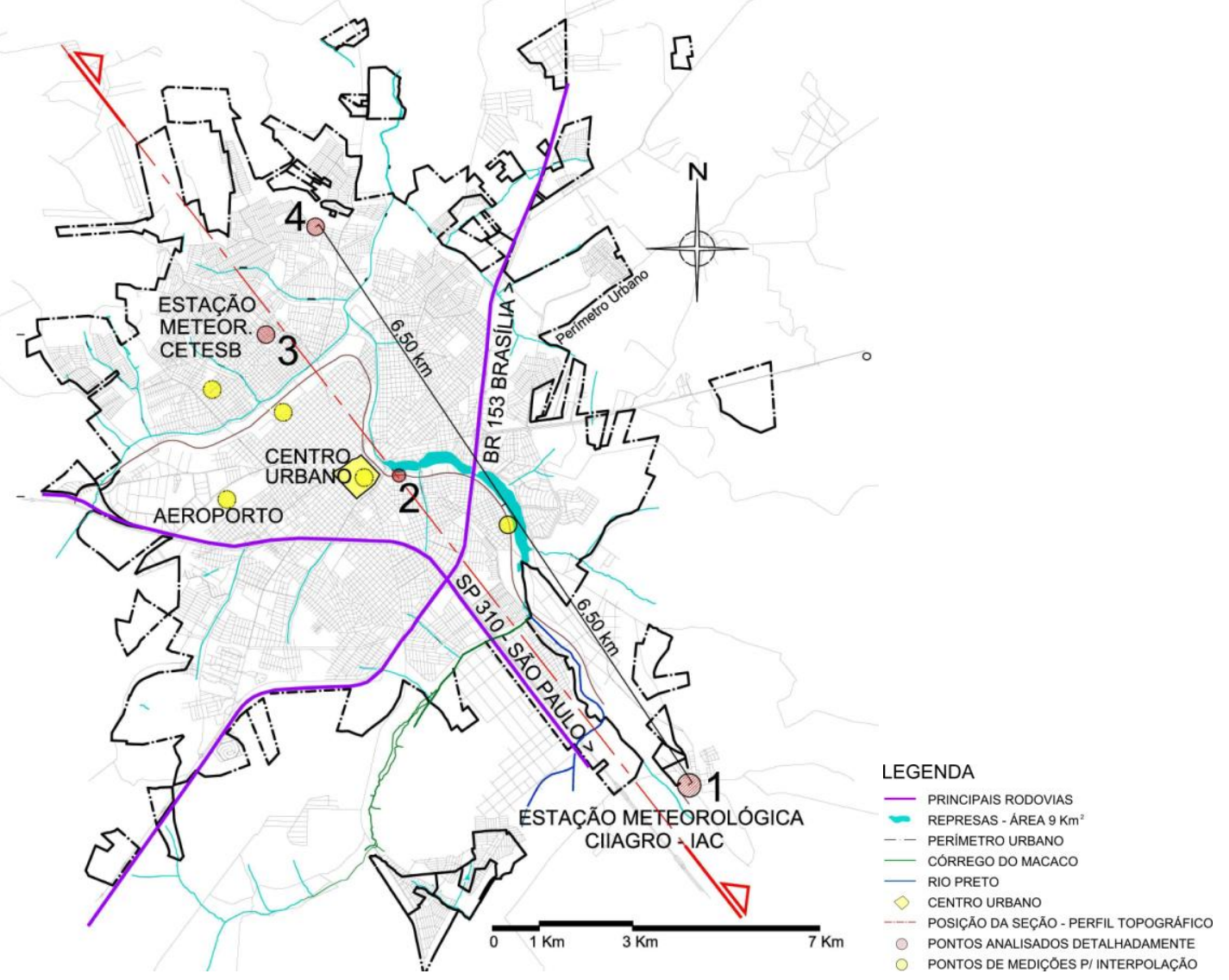

Fonte: adaptado de Prefeitura Municipal de São José do Rio Preto (2013a).

Figura 5 - Perfil topográfico da área urbana de São José do Rio Preto

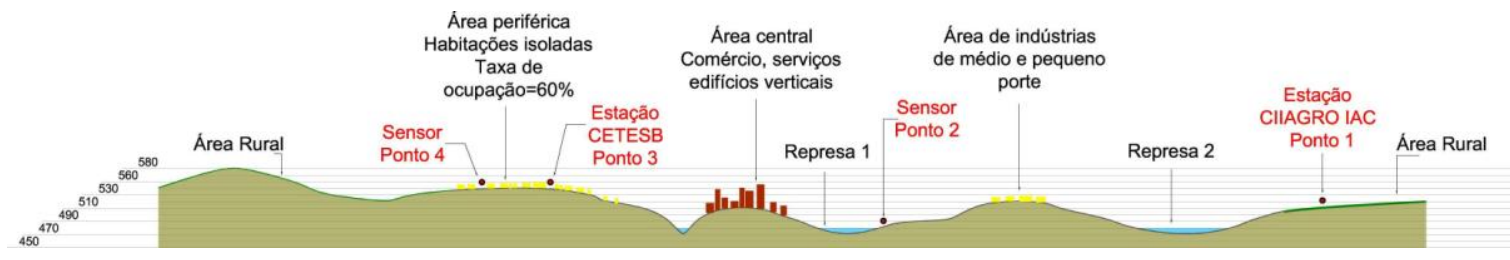

Figura 6 - Imagens dos pontos de coleta de dados

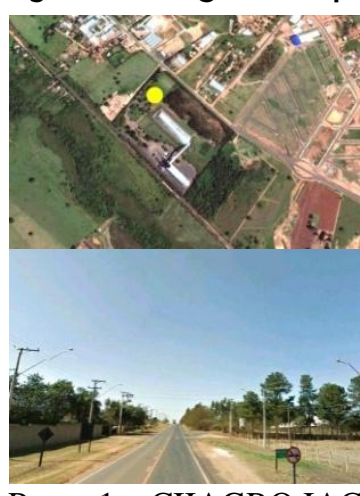

Ponto 1 - CIIAGRO IAC - Zona Rural

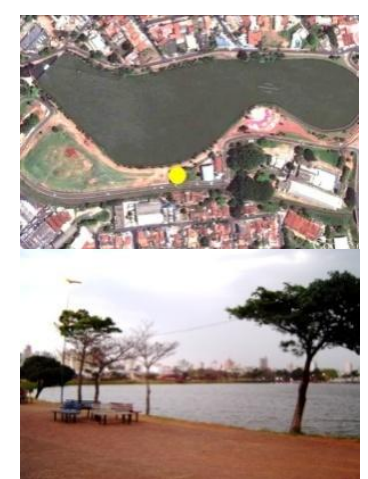

Ponto 2 - Represa

Zona Urbana Baixa Densidade

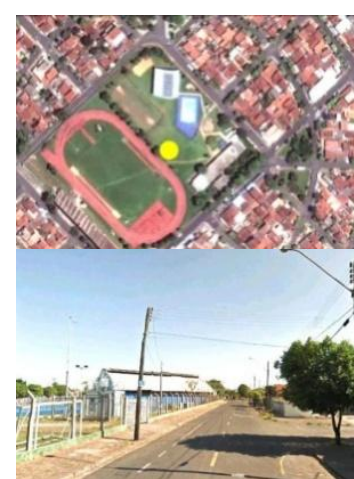

Ponto 3 - CETESB

Zona Residencial Urbana

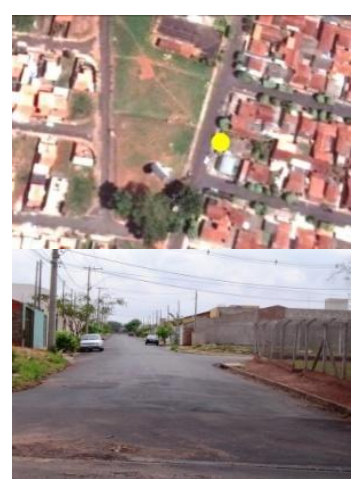

Ponto 4 - Zona Norte Residencial Urbana

Fonte: fotos do autor (2012) e adaptação de imagens do Google Earth (2013). 
Figura 7 - Sensor HOBO Pro V2 U23-001, escudo de PVC contra radiação e especificações

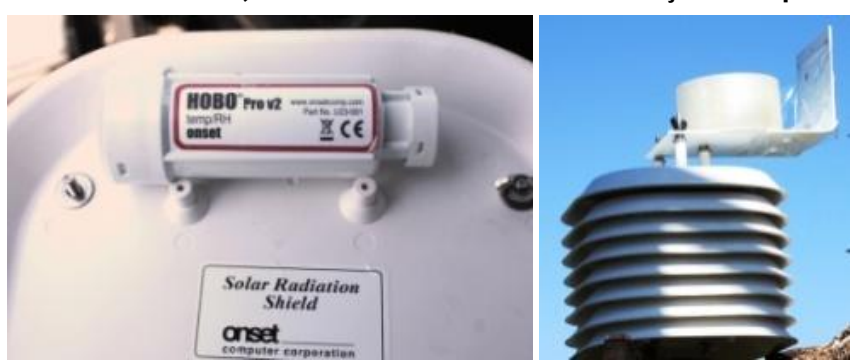

Nota: Faixa de operação: $-40^{\circ} \mathrm{C}$ a $70^{\circ} \mathrm{C}$;

Precisão: $\pm 0,2^{\circ} \mathrm{C}$ acima de $0{ }^{\circ} \mathrm{C}$ até $50^{\circ} \mathrm{C}$;

Resolução: $0,02{ }^{\circ} \mathrm{C}$ a $25^{\circ} \mathrm{C}$; e

Tempo de resposta: 40 minutos no ar em movimento de $1 \mathrm{~m} / \mathrm{s}$.

Figura 8 - Altura de instalação dos sensores

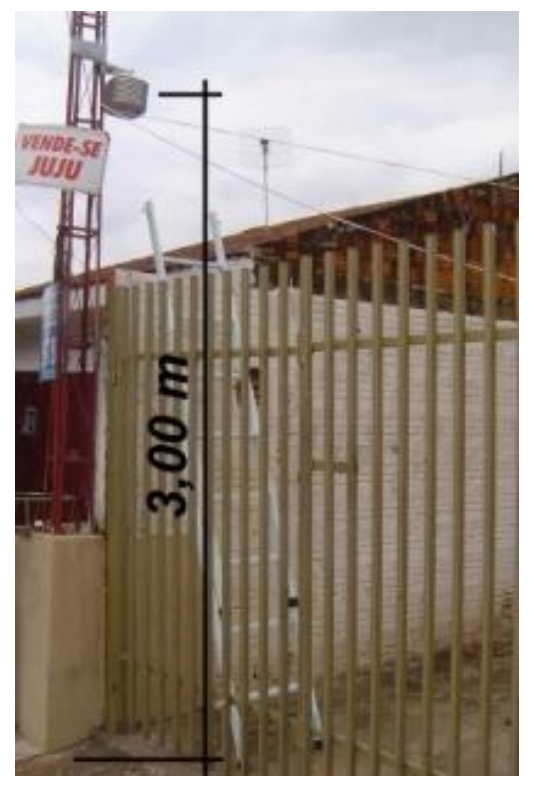

Após a campanha de coleta de dados, foram estabelecidas analogias entre os dados observados e os dados meteorológicos disponibilizados pelo Instituto Nacional de Pesquisas Espaciais, Centro de Previsão do Tempo e Estudos Climáticos (CENTRO..., 2013a). A intenção foi compreender como os fenômenos macroclimáticos são associados às condições microclimáticas na escala urbana. No mês de outubro de 2012 as temperaturas permaneceram elevadas em decorrência da ação intensa da Massa Tropical Continental, que se forma normalmente na zona do Chaco, região norte da Argentina, e se desloca para o interior do Brasil. Esse fenômeno atua frequentemente nessa época do ano e imprime as características quente e seco ao tempo. A sequência das imagens captadas pelo Satélite GOES nos dias 5, 6 e 7 de outubro sobre a região de estudo evidencia a tendência de redução da umidade, com redução gradativa de nuvens e tendência de aumento de temperatura durante esses três dias (Figura 9). Essa sequência de imagens favoreceu o registro da ação da umidade do ar sobre a malha urbana.

\section{Determinação da janela de tempo para análise dos dados}

Os períodos mais quentes e secos foram selecionados de forma que a detecção da influência da umidade proveniente do corpo d'água ficasse mais evidente. Após o tratamento dos dados e a confecção dos gráficos analíticos, foi realizado o cálculo da umidade absoluta, através da carta psicrométrica. A relação psicrométrica desse fenômeno foi realizada com o auxílio do programa computacional Psicrom 1.0 (RORIZ, 2003). 
Figura 9 - Imagens do Satélite GOES dos dias 5, 6 e 7 de outubro de 2012 - tendência de redução de umidade
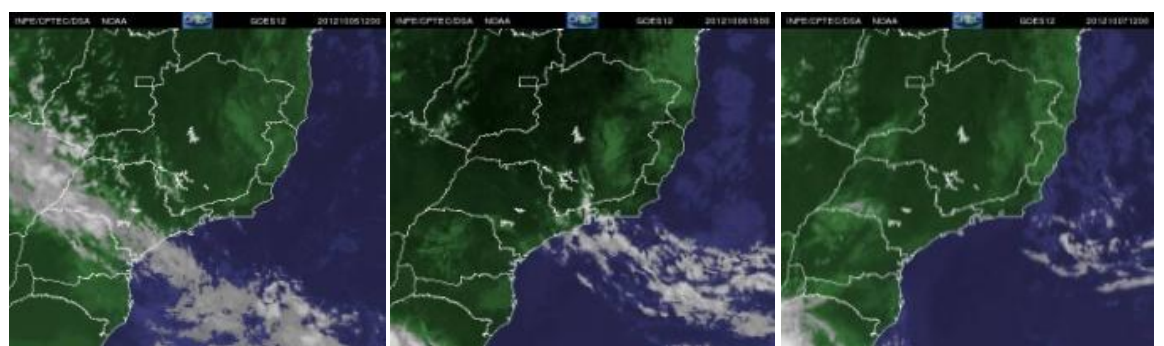

Fonte: Centro de Previsão de Tempo e Estudos Climáticos (2013b).

\section{Modelagem e mapeamento}

O comportamento das variações de temperatura e de umidade absoluta pode ser associado às condições físicas e geográficas de implantação de São José do Rio Preto. O horário mais quente e seco foi analisado com o auxílio do programa computacional Surfer 8, o qual foi aplicado para estabelecer graficamente as diferenças intraurbanas entre os dados coletados, através do mapeamento das informações.

Os dados coletados nos nove pontos espalhados pela malha urbana foram interpolados pelo método da Krigagem para estimar a variação de valores entre eles. A Krigagem consiste em um método matemático utilizado em geoestatística que estabelece pesos maiores nas posições mais próximas aos pontos amostrais e pesos menores nas posições mais afastadas. Dessa forma, é possível estimar novos pontos baseados na relação entre os dados coletados.

Monteiro e Mendonça (2011) recomendam buscar embasamento cartográfico e setorizar a ocupação urbana em determinadas frações relativamente homogêneas. Os dados de densidade construída, porção de áreas verdes abertas ou pavimentadas, áreas arborizadas, da topografia, dos cursos d'água e a relação entre altura e largura dos cânions puderam ser obtidos através das bases cartográficas da Prefeitura Municipal, dos levantamentos in loco e das imagens de satélites. Ao propor o estudo detalhado dos diferentes ambientes climáticos intraurbanos, é possível identificar os agentes responsáveis pela dinâmica dos espaços construídos, para que sugestões junto ao planejamento urbano sejam conferidas com maior embasamento técnico.

\section{Análise gráfica e qualitativa da distribuição da umidade absoluta}

Após a localização dos dados coletados através do mapeamento, foi feita uma análise gráfica e qualitativa da distribuição da umidade absoluta pela malha urbana, sob diversas condições climáticas, e estabelecidas as relações com as características físicas, geográficas e de uso e ocupação do solo da cidade.

\section{Resultados}

Os resultados para a temperatura do ar são demonstrados na Figura 10. Foi detectado que o ponto 2 (margem da represa) permaneceu em média aproximadamente $2{ }^{\circ} \mathrm{C}$ abaixo do ponto 4 (zona norte residencial) nos horários mais quentes dos três dias de mediação. Tal fato está relacionado à abundante presença de água no ponto 2 e à escassez de elementos que contribuam para a umidificação do ar no ponto 4 , principalmente pelo baixo índice de áreas verdes da área norte da cidade. $\mathrm{O}$ fenômeno do resfriamento evaporativo adiabático, que ocorre com maior intensidade no ponto 2 , pode ser observado como resultado do fluxo de ar que atravessa um meio úmido e favorece a evaporação da água junto com a redução da temperatura do ar.

Vale ressaltar que, devido ao uso de diferentes tipos de sensores durante a etapa de coleta de dados, a imprecisão dos resultados pode chegar a até $\pm 0,5^{\circ} \mathrm{C}$ entre os quatro pontos estudados.

A alta taxa de impermeabilização do solo favorece a rápida evaporação e também contribui para que a retenção da umidade no ambiente urbano seja reduzida. Foi registrada uma diferença de aproximadamente $7 \mathrm{~g} / \mathrm{m}^{3}$ entre o ponto 2 (margem da represa) e o ponto 4 (zona norte residencial), no horário mais seco do estudo, ou seja, às $10 \mathrm{~h}$ do dia 7 de outubro de 2012 (Figura 11).

Os valores de umidade relativa do ar também apresentaram variações excessivas entre os diversos pontos medidos na área urbana, de modo que fica evidente a forte influência da composição dos elementos urbanos na qualidade do ambiente térmico. No dia 7 de outubro de 2012 a máxima diferença registrada foi de aproximadamente $32 \%$ entre o ponto mais seco e o mais úmido (Figura 12).

32 Masiero, E.; Souza, L. C. L. de. 
Figura 10 - Variação da temperatura do ar entre quatro pontos urbanos

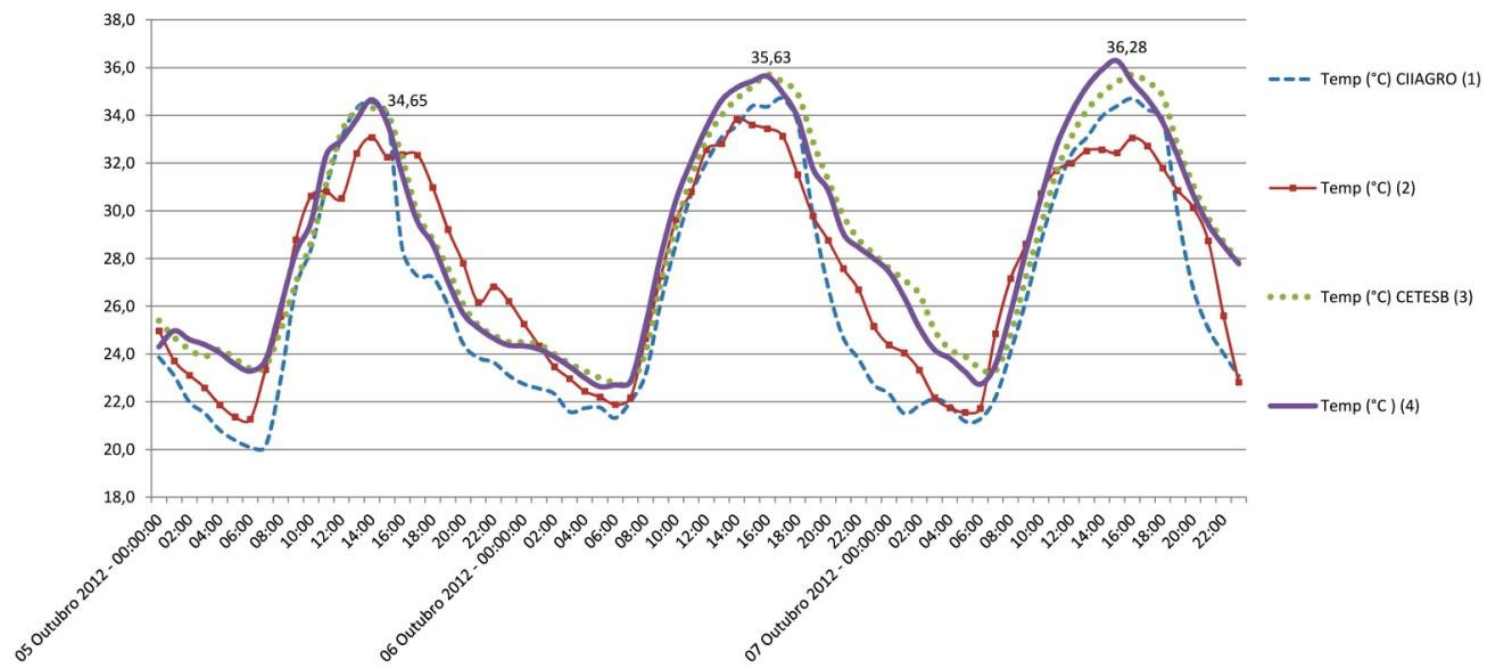

Figura 11 - Variação da umidade absoluta entre quatro pontos urbanos

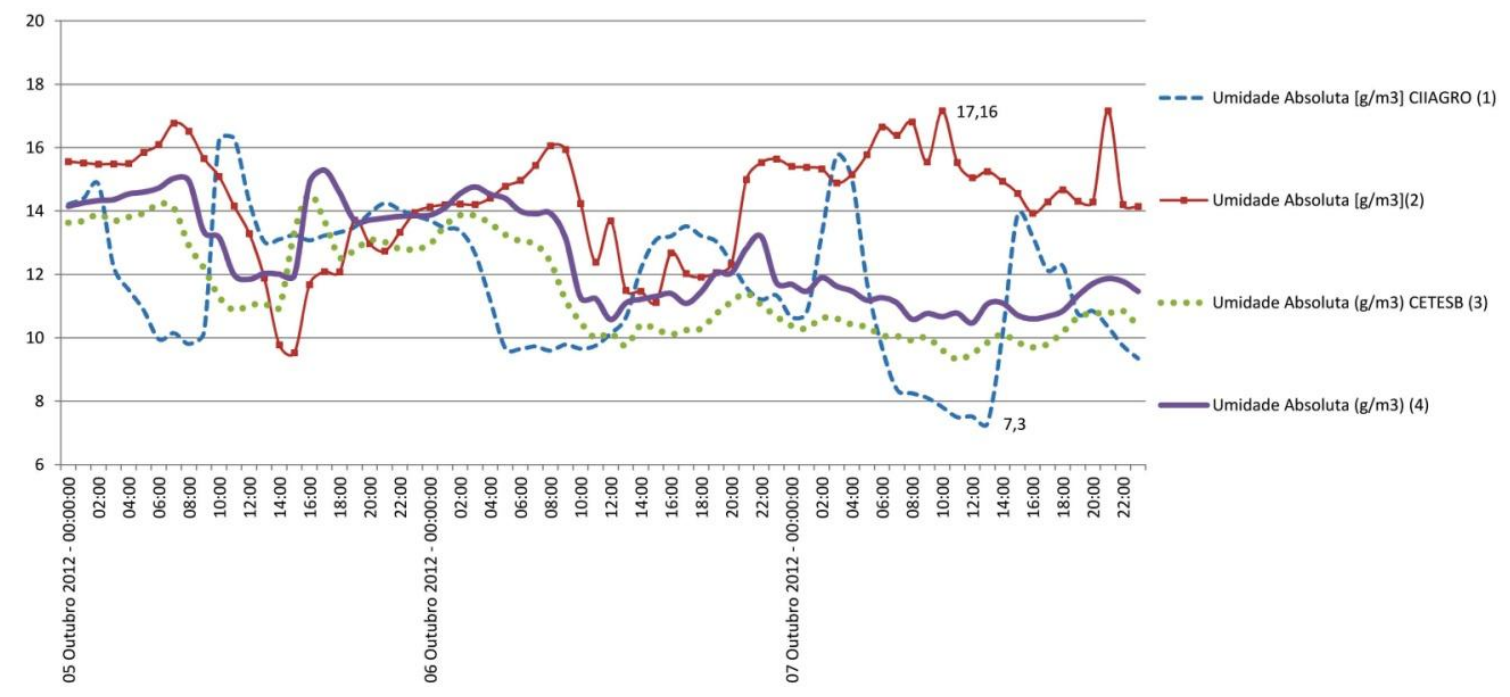

Figura 12 - Variação da umidade relativa entre quatro pontos urbanos

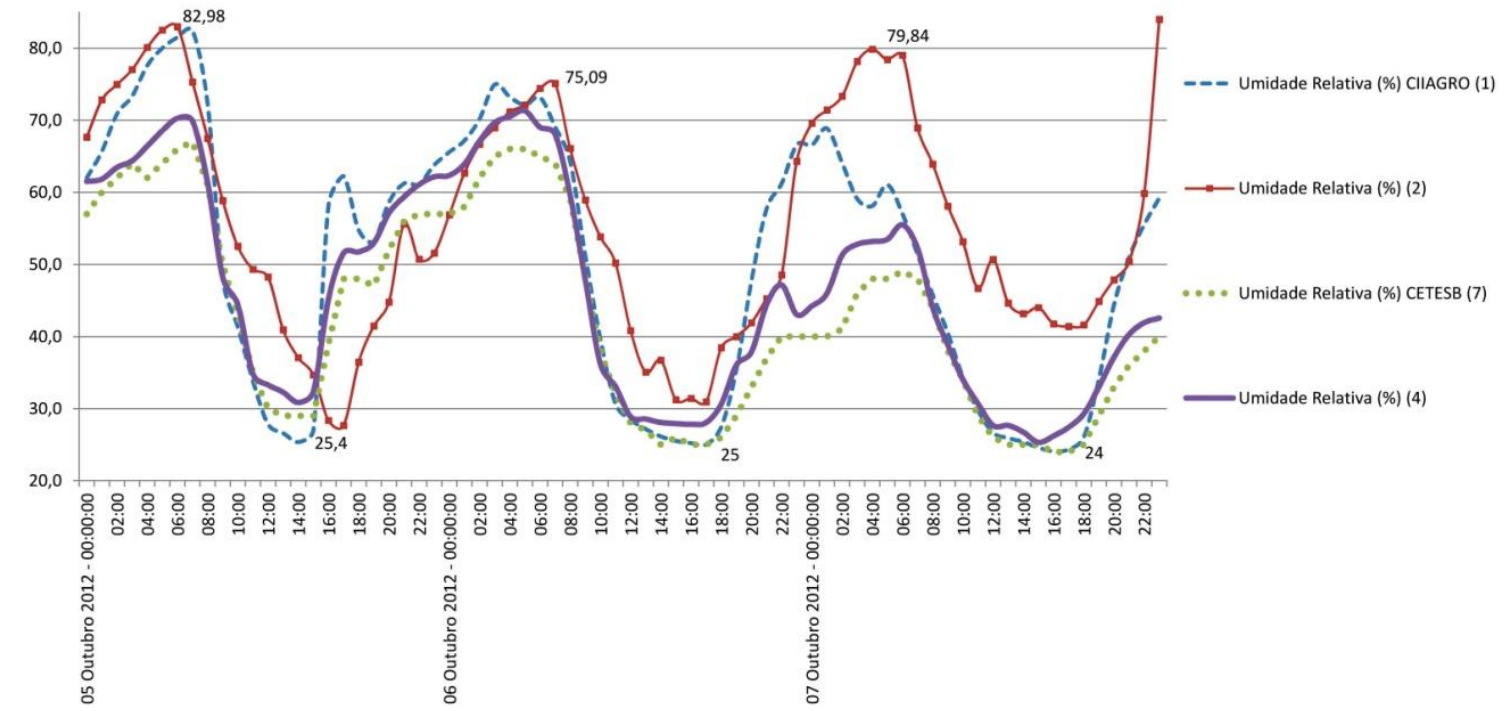


A Figura 13 apresenta a variação dos índices de umidade absoluta no ponto 2 , de acordo com a atuação da direção do vento. É possível compreender que, conforme o vento soprou de oeste para leste no dia 5 de outubro de 2012, os índices de umidade foram fortemente reduzidos, consequência da perda de umidade da massa de ar ao atravessar a área urbana antes de atingir o sensor. Conforme o vento soprou de leste para oeste, a massa de ar foi umidificada pela água da represa antes de atingir o sensor, e, portanto, os índices de umidade absoluta registrados foram maiores no dia 7 de outubro de 2012.

O estudo das condições de temperatura e umidade através de mapeamento contribuiu para uma análise genérica dos fenômenos envolvidos de trocas de calor no ambiente urbano e para a compreensão da tendência de comportamento e dos limites de influência do corpo d'água.

A Figura 14 apresenta o mapeamento da distribuição dos valores de temperatura que ocorreram no dia 7 de outubro de 2012 às 15h. É possível verificar graficamente que a área ao redor da represa municipal apresenta as temperaturas mais amenas da cidade. Inclusive, a área central, a qual é a de ocupação mais densa e impermeabilizada, não apresenta os maiores índices de temperatura do município, devido a sua proximidade com o corpo d'água. Embora o sombreamento provocado pelo conjunto de edifícios nos cânions urbanos possa contribuir para o registro das temperaturas mais baixas no centro da cidade do que as da área norte, destaca-se que a presença da umidade nas áreas centrais influi de fato nos valores de temperatura.

Outro fator de suma importância refere-se à diferença de cota de nível existente entre a zona norte e a zona sul da cidade. Pelo fato de a zona norte estar situada na região mais elevada, é provável que a umidade disponibilizada pela represa municipal não influencie significativamente nas condições térmicas, de modo que a umidade do ar tende a se distribuir mais facilmente pelos vales em um entorno imediato, dependendo das condições de vento. Dessa forma, recomenda-se que o planejamento urbano produza mecanismos que tanto contribuam para a permeabilidade ao vento como também crie estratégias de redução das taxas de evaporação nas áreas periféricas da cidade.

Figura 13 - Variação da umidade absoluta comparada com a atuação do vento no ponto 2

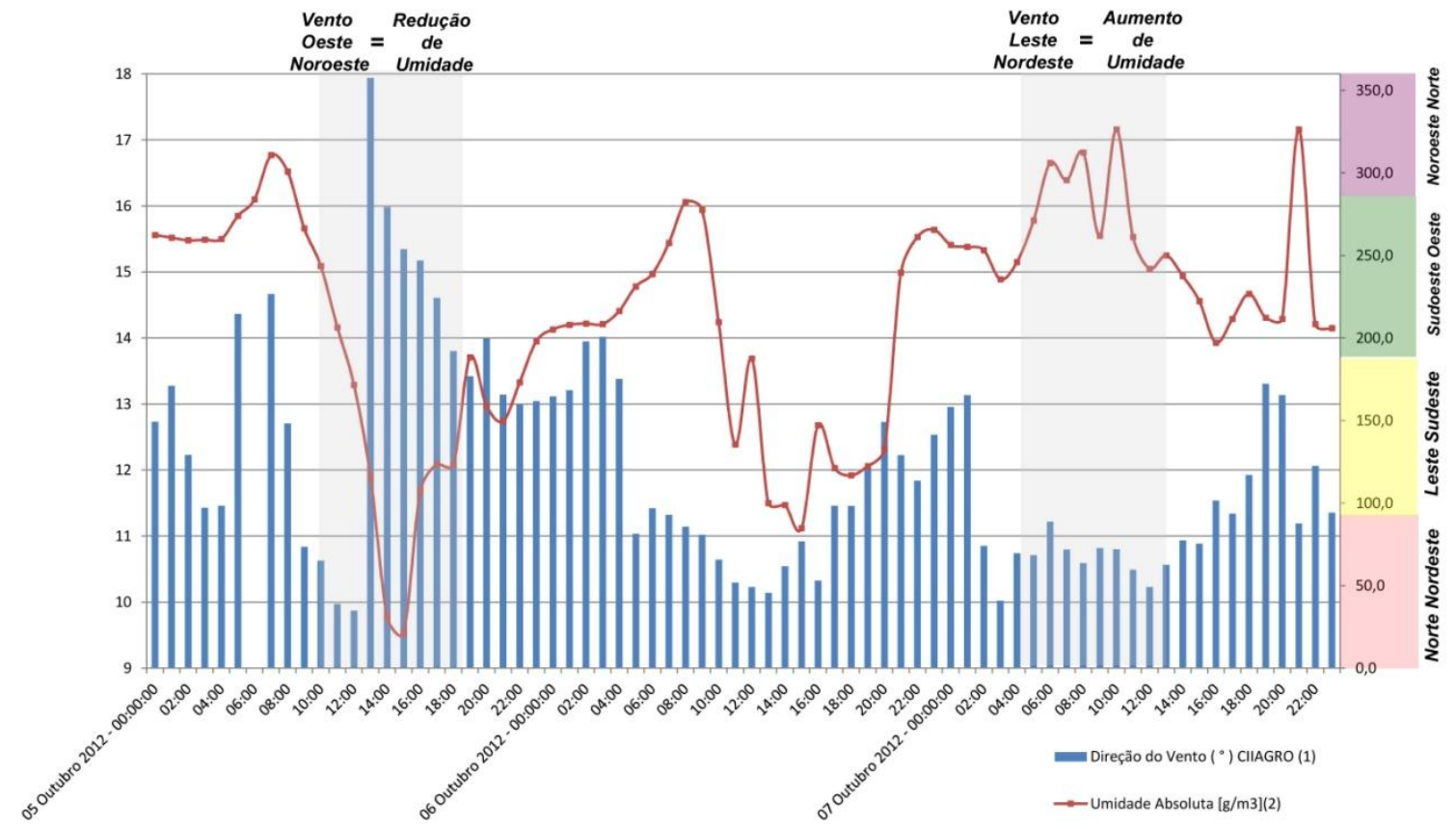

34 Masiero, E.; Souza, L. C. L. de. 
Figura 14 - Distribuição dos valores de temperatura - tendência de aumento na área norte

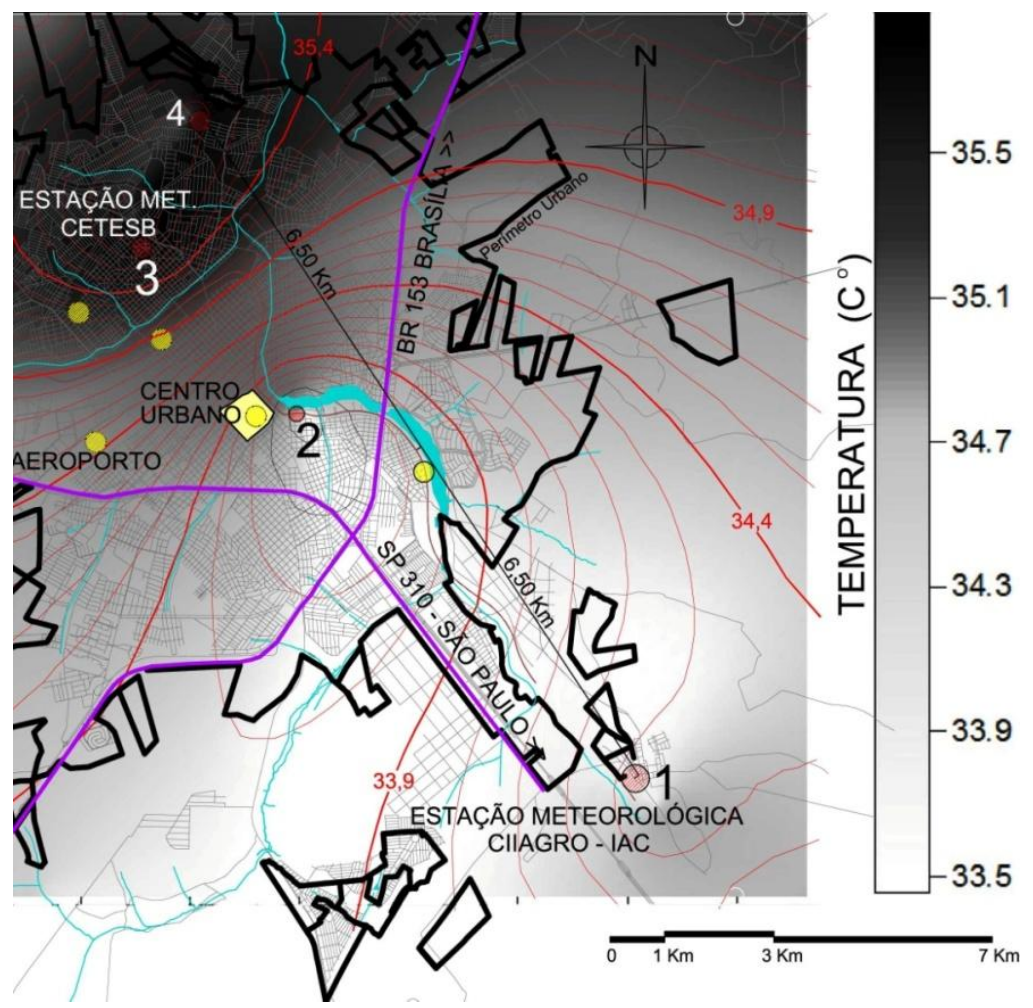

A Figura 15 apresenta a localização através de mapeamento da distribuição dos valores de umidade absoluta. Foi escolhido o dia 7 de outubro 2012 às $10 \mathrm{~h}$ por ser o momento que apresentou as maiores variações ao longo do período de estudo. Constata-se que a represa municipal representa um importante elemento urbano para a criação de condições microclimáticas mais agradáveis na região central. No entanto, o perfil topográfico natural e a ocupação mais adensada no sentido nordeste-sudoeste são fatores decisivos que prejudicam a permeabilidade aos ventos e a distribuição homogênea da umidade. Ambos os fatores se tornam barreiras, que impedem que a combinação de ventos com a umidade da represa atinja as áreas mais elevadas e áridas da cidade, situadas na zona norte.

Os mapas de distribuição de temperatura e umidade são resultados de interpolações de valores monitorados em poucos pontos em campo e apresentam aproximações decorrentes dos cálculos geoestatísticos da Krigagem, de forma que a precisão do estudo pode aumentar, com o aumento do número de pontos.

\section{Discussão}

As elevadas diferenças de temperatura e umidade do ar constatadas entre as áreas sul e norte da cidade apresentam o efeito do resfriamento evaporativo como o principal fator de influência. No entanto, a ocorrência da evaporação da água e a distribuição da umidade do ar intraurbano estão relacionadas, principalmente, às características climáticas predominantes de uma região, à configuração do ambiente construído e vegetado e à disponibilidade de recursos hídricos locais, de forma que a interação entre esse conjunto de fatores contribui para o comportamento térmico do espaço urbano.

Como a cidade de São José do Rio Preto está situada em uma região continental com clima Tropical de Altitude, a umidade relativa do ar atinge frequentemente índices abaixo de $20 \%$, principalmente nos meses mais secos de inverno. Em situações de atmosfera quente e seca, Krüger e Pearlmutter (2008) relatam que o efeito do resfriamento evaporativo em cânions urbanos afeta de maneira efetiva os índices de temperatura e umidade. A amplitude térmica diária em climas secos costuma ser elevada em função dos baixos índices de umidade, e quanto maior a quantidade de água na atmosfera, menor será a variação térmica ao longo do dia. Assim, o incremento de umidade em cidades que se situam nessas áreas pode reduzir a amplitude térmica diária e tornar o ambiente menos agressivo ao corpo humano. 
Figura 15 - Distribuição dos valores de umidade absoluta - tendência da redução na área norte

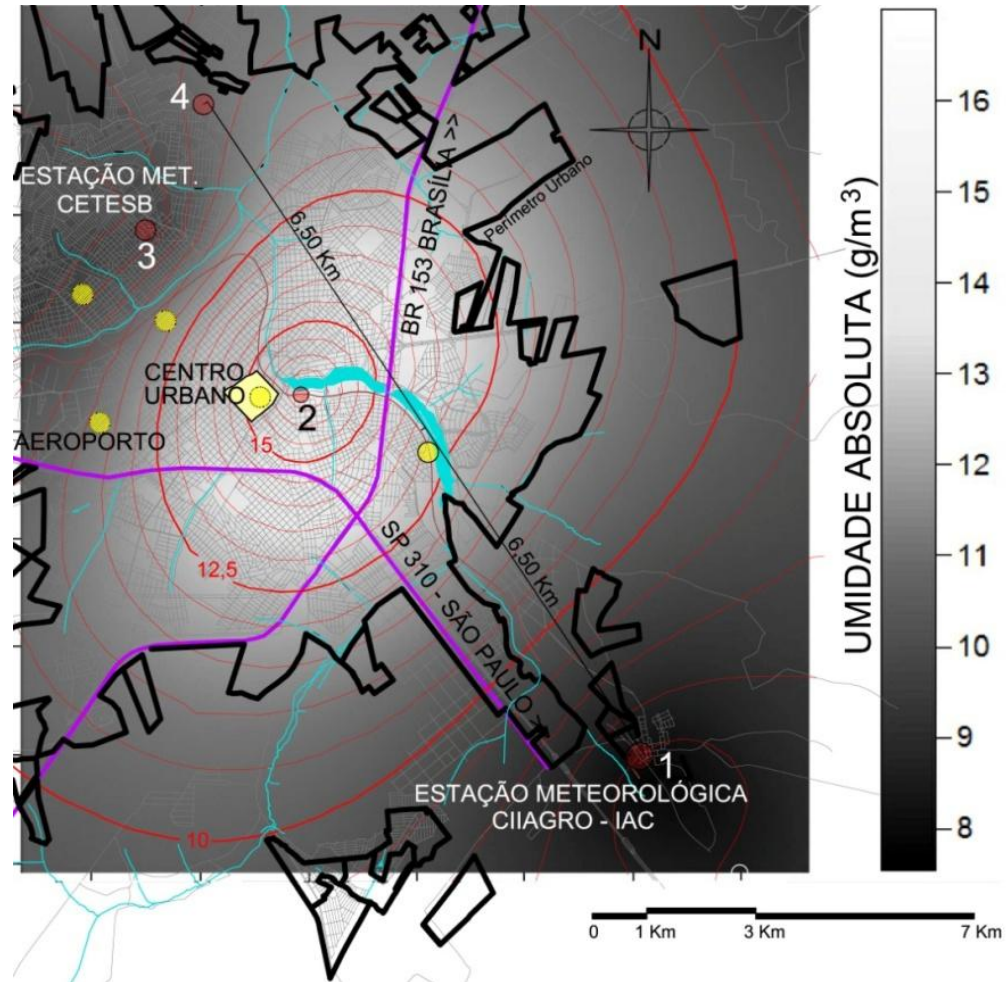

É importante salientar que durante a noite as áreas mais úmidas de uma cidade tendem a perder menos calor que as secas. Portanto, a umidade tanto pode favorecer a criação de ambientes mais amenos durante o dia como pode criar ambientes abafados durante a noite, caso haja pouca disponibilidade de ventos. Emmanuel e Johansson (2006) constataram que com os ventos moderados o clima quente e úmido em Colombo, Sri Lanka, e a alta densidade da ocupação urbana contribuem para o excessivo acúmulo de umidade nos cânions, assim a brisa marítima não chega a beneficiar o microclima da região central da cidade. Neste caso, a pouca preocupação por parte do planejamento em direcionar a implantação dos cânions, somada aos baixos índices de ventilação urbana, não favorece a dispersão e a distribuição da umidade do ar. No caso de São José do Rio Preto, o relevo e a ocupação verticalizada da área central impedem que os ventos provenientes de sul e sudeste distribuam a umidade do ar disponibilizada pela represa até as áreas mais elevadas da cidade. Tal fato elucida que, apesar de a região dispor de recursos hídricos e de potencial eólico, a implantação da malha urbana também não aproveita o potencial natural para garantir qualidade térmica do espaço urbano.

Pode-se ainda estabelecer uma comparação entre outros resultados apontados na literatura e os aqui obtidos. Em Osaka, no Japão, a administração pública da cidade propôs o uso do potencial de resfriamento das brisas marítimas para mitigar os efeitos do rigor térmico dos meses de verão. Aquele trabalho de Yoshida et al. (2012) revelou uma diferença de $2{ }^{\circ} \mathrm{C}$ em média entre as áreas planejadas para captar e distribuir a umidade do ar no distrito de Nakanoshima e as áreas adjacentes sem o mesmo rigor de planejamento. Resultados muito similares também foram relatados por Wong, Tan e Jusuf (2012), que investigaram a influência de um corpo d'água na temperatura do ar em Cingapura. Foi observado naquele estudo que a diferença de temperatura entre os pontos analisados na malha urbana permaneceram entre $0,6{ }^{\circ} \mathrm{C}$ e $2{ }^{\circ} \mathrm{C}$ entre os mais distantes e os mais próximos do corpo d'água. No caso do estudo desenvolvido em São José do Rio Preto, foi detectado que a área da margem do corpo d'água permaneceu em média $2{ }^{\circ} \mathrm{C}$ abaixo da área mais distante, entretanto os resultados referentes ao comportamento da umidade absoluta no ambiente urbano ainda são escassos.

Os resultados apresentados e os fenômenos físicos detectados nesses estudos são condizentes com a literatura científica e reforçam a necessidade de intervenção do poder público no desenho urbano. Tanto os procedimentos metodológicos aplicados quanto os resultados das pesquisas aqui apresentadas apontam para a necessidade de uma aproximação cada vez maior da climatologia com 
o planejamento urbano. Portanto, é importante que os tomadores de decisão considerem questões relativas ao clima urbano nas futuras intervenções no espaço físico, para equilibrar a qualidade térmica das diversas regiões da cidade.

O fato de a região de São José do Rio Preto possuir recursos hídricos em abundância e a alta variação dos valores de temperatura e umidade absoluta do ar detectada neste estudo corroboram a necessidade de serem criadas estratégias para a redução da evaporação nas áreas periféricas e melhoria da distribuição da umidade da represa municipal pela malha urbana.

\section{Conclusões}

O aproveitamento dos recursos climáticos, combinado com o potencial dos elementos naturais, é uma das estratégias recomendadas para garantir ambientes mais saudáveis e agradáveis. Dessa forma, o estudo da interação entre ventos e corpos d'água pode esclarecer o alto potencial de controle microclimático através de recursos passivos e naturais disponíveis.

Destaca-se que a ação do vento sobre a massa d'água pode influenciar seu entorno imediato, chegando a alcançar até $1.000 \quad \mathrm{~m}$ aproximadamente, dependendo das características topográficas, por umidificar o ar urbano e reduzir a amplitude térmica diária. No entanto, a expressiva diferença detectada nos índices de temperatura e umidade nas camadas intraurbanas esclarece que os $9 \mathrm{~km}^{2}$ da represa municipal, situada nas cotas de níveis mais baixas da cidade, não são suficientes para influenciar a zona norte sob quaisquer condições de vento. Inclusive, a umidade presente nos vales pouco penetra no tecido urbano localizado nas cotas de níveis mais elevadas. O relevo e o adensamento das edificações predominantes no sentido nordeste-sudoeste contribuem para diminuir a ação dos ventos na distribuição da umidade. Tais fatores impedem que a interação dinâmica entre o potencial eólico e a umidade da represa atinja as áreas mais elevadas e áridas da cidade, situadas na zona norte.

Dessa maneira, a amplitude térmica próxima da represa apresenta valores menores e, conforme o ambiente se torne mais árido e urbanizado, uma maior amplitude térmica poderá ser observada, fato que deve ser levado em consideração para a determinação de estratégias que criem microclimas e garantam a qualidade do espaço construído como um todo. A inserção de umidade através do represamento de rios e córregos pode ser uma estratégia viável de planejamento urbano para a melhoria das condições do ambiente térmico urbano em cidades situadas em regiões continentais com clima predominantemente quente e seco.

\section{Referências}

ARNFIELD, A. J. Review: two decades of urban climate research: a review of turbulence, exchanges of energy and water, and the urban heat island. International Journal of Climatology, v. 23, n. 1, p. 1-26, 2003.

ASSIS, E. S. Aplicações da Climatologia Urbana no Planejamento da Cidade: revisão dos estudos brasileiros. Revista de Urbanismo e Arquitetura Rua, v. 7, n. 1, 2006.

\section{CENTRO DE PREVISÃO DE TEMPO E} ESTUDOS CLIMÁTICOS. Boletim Climanálise Disponível em: <http://infoclima1.cptec.inpe.br/>. Acesso em: 27 nov. $2013 \mathrm{a}$

\section{CENTRO DE PREVISÃO DE TEMPO E ESTUDOS CLIMÁTICOS. Setores Sudeste. Disponível em: \\ <http://satelite.cptec.inpe.br/setores/sudeste.jsp>. Acesso em: 27 nov. 2013 b.}

\section{CENTRO INTEGRADO DE INFORMAÇÕES AGRO METEOROLÓGICAS. Monitoramento das Estações. Disponível em:}

<http://www.ciiagro.org.br/ema/monitoramento.ph p>. Acesso em: 27 nov. 2013c.

CHEN, L.; NG, E. Quantitative Urban Climate Mapping Based on a Geographical Database: a simulation approach using Hong Kong as a case study. International Journal of Applied Earth Observation and Geoinformation, v. 13, n. 4, p. 586-594, ago. 2011.

COMPANHIA AMBIENTAL DO ESTADO DE SÃO PAULO. Sistema Qualar: qualidade do ar. Disponível em:

<http://qualar.cetesb.sp.gov.br/qualar/home.do>. Acesso em: 27 nov. 2013.

EMMANUEL, R.; JOHANSSON, E. Influence of Urban Morphology and Sea Breeze on Hot Humid Microclimate: the case of Colombo, Sri Lanka.

Climate Research, v. 30, n. 3, p. 189-200, 2006.

GRIMMOND, C. S. B.; OKE, T. R.

Evapotranspiration Rates in Urban Areas. Impacts of Urban Growth on Sur/au Water and Groundwater Quality. In: IUGG 99 SYMPOSIUM HSS, Birmingham, 1999. Proceedings... Birmingham, 1999.

GOOGLE EARTH 7.1.2.2041. Disponível em: <http://earth.google.com/>. Acesso em: 27 Nov. 2013. 
INSTITUTO BRASILEIRO DE GEOGRAFIA E ESTATÍSTICA. Cidades. Disponível em: <http://www.ibge.gov.br/cidadesat/topwindow.htm ?1>. Acesso em: 27 nov. 2013.

KRÜGER, E. L.; PEARLMUTTER, D. The Effect of Urban Evaporation on Building Energy Demand in an Arid Environment. Energy and Buildings, v. 40, n. 11, p. 2090-2098, 2008.

KUTTLER, W. et al. Urban/Rural Atmospheric Water Vapour Pressure Differences and Urban Moisture Excess in Krefeld, Germany.

International Journal of Climatology, v. 27, n. 14, p. 2005-2015, 2007.

MILLS, G. et al. Climate Information For Improved Planning and Management of Mega Cities (Needs Perspective). Environmental Sciences, v. 1, p. 228-246, 2010.

MITCHELL, V. G. et al. Linking Urban Water Balance and Energy Balance Models to Analyze Urban Design Options. Hydrological Process, 2007.

MONTEIRO, C. A. F.; MENDONÇA, F. Clima Urbano. 2. ed. São Paulo: Contexto, 2011.

MONTEIRO, C. A. F. A Dinâmica Climática e as Chuvas do Estado de São Paulo: estudo geográfico sob forma de Atlas. São Paulo: Universidade de São Paulo - Instituto de Geografia, 1973.

NIMER, E. Climatologia do Brasil. Rio de Janeiro: IBGE, 1979.

OKE, T. R. Initial Guidance to Obtain Representative Meteorological Observations at Urban Sites. Vancouver: World Meteorological Organization. Instruments and Observing Methods. 2006. Report No. 81.

PREFEITURA MUNICIPAL DE SÃO JOSÉ DO RIO PRETO. Secretaria de Planejamento e Gestão Estratégica Municipal. Mapas de São José do Rio Preto. Disponível em:

<http://www.riopreto.sp.gov.br/PortalGOV/do/sub portais_Show?c $=5050>$. Acesso em: 27 nov. 2013a.
PREFEITURA MUNICIPAL DE SÃO JOSÉ DO RIO PRETO. Secretaria de Planejamento e Gestão Estratégica Municipal. Conjuntura Econômica de São José do Rio Preto. Disponível em: <http://www.riopreto.sp.gov.br/PortalGOV/do/sub portais_Show?c=5050>. Acesso em: 27 nov. $2013 b$

ROCHA, L. M. V.; SOUZA, L. C. L.; CASTILHO, F. J. V. Ocupação do Solo e Ilha de Calor Noturna em Avenidas Marginais a Um Córrego Urbano. Ambiente Construído, Porto Alegre, v. 11, n. 3, p. 161-175, out./dez. 2011.

RORIZ, M. PSICROM 1.0: programa computacional desenvolvido para cálculos de relações psicrométricas. São Carlos: Universidade Federal de São Carlos, Departamento de Engenharia Civil, Programa de Pós Graduação em Construção Civil, 2003.

WONG, N. H.; TAN, E.; JUSUF, S. K. Influence of Water Body on Air Temperature in Singapore Climate. In: INTERNATIONAL CONFERENCE ON URBAN CLIMATES, 8., Dublin, 2012, Dublin. Proceedings... Dublin, 2012.

YOSHIDA, A. et al. Mobile Observation of Air Temperature and Humidity Distributions in Osaka - Nakanoshima Area During Summer Sea Breeze. In: INTERNATIONAL CONFERENCE ON URBAN CLIMATES, 8., Dublin, 2012. Proceedingss... Dublin, 2012.

YUAN, C. et al. Improving the Wind Environment in High-density Cities By Understanding Urban Morphology and Surface Roughness: a study in Hong Kong. Landscape and Urban Planning, v. 101, n. 1, p. 59-74, 2011.

\section{Agradecimentos}

Os autores agradecem à Capes, pelo apoio financeiro, ao Serviço Municipal Autônomo de Água e Esgoto SEMAE, a Telma, ao Rodrigo e ao Sr. Antônio da Escola Renascer, ao Sindicato dos Servidores Públicos Municipais de S. J. Rio Preto, à Canção Nova, à Companhia de Tecnologia de Saneamento Ambiental do Estado de São Paulo, ao Instituto Agronômico de Campinas, a Giovanna Wakamatu, a Graziela W. Davoglio, ao Alex Davoglio, ao Sr. Pedro Wakamatu e ao Sr. dos Santos do Aeroporto Eriberto Reino, pelo apoio prestado à realização desta pesquisa. 
Erico Masiero

Programa de Pós Graduação em Engenharia Urbana | Universidade Federal de São Carlos | Rod. Washington Luis, Km 235 | São Carlos - SP - Brasil | CEP 13565-905 | Tel.: (16) 3351-8295 | E-mail: ericomasiero@yahoo.com.br

\section{Léa Cristina Lucas de Souza}

Centro de Ciências Exatas e de Tecnologia | Universidade Federal de São Carlos | Tel.: (16) 3351-8232 | E-mail: leacrist@ufscar.br

\section{Revista Ambiente Construído}

Associação Nacional de Tecnologia do Ambiente Construído

Av. Osvaldo Aranha, $99-3^{\circ}$ andar, Centro

Porto Alegre - RS - Brasil

CEP $90035-190$

Telefone: +55 (51) 3308-4084

Fax: +55 (51) 3308-4054

www.seer.ufrgs.br/ambienteconstruido

E-mail: ambienteconstruido@ufrgs.br 